\title{
Testing Forecasting Method:Displacement of Bottled LPG by Pipelined Gas in the Brazilian Dwelling Sector, a 2004Essay Revisited
}

\author{
Arlindo Kamimura ${ }^{* 1}$, Geraldo F. Burani ${ }^{1}$ and Ildo L. Sauer ${ }^{1}$ \\ ${ }^{I}$ IEE - Institute of Energy and Environment, University of São Paulo, Av. Prof. Luciano Gualberto, 1289. \\ 05508-900 - São Paulo, SP, Brazil
}

\begin{abstract}
Thecompetition between two energy sources for the same market which results in the replacement of one source by the other, based on dynamic model derived from biomathematics, previously applied in 2004, by authors in the Brazilian LPG x Pipelined NG (PNG)dwellingconsumption market is analyzed. The proposed model seems to be useful to increase the knowledge of the relationship between input and output variables in a system and the results can improve the communication rapport between theoretical modelers and decision makers. The forecasting results are compared with the actual data.
\end{abstract}

Keywords: Non Linear Differential Equations; Forecasting; Fuel substitution; Market Share

\section{INTRODUCTION}

In an essay done in 2004 and published in 2006 [1], the authors proposed a model derived from biomathematics, in which a coupled set of non-linear differential equations is settled to describe the competition between two energy sources for the same market. The adherence of the proposed model to explain several substitution phenomena occurred in the past was presented, as well as the application of the modelto examine prospectively the dynamic substitution process in the Brazilian dwelling sector: the urban natural gas pipeline PNG in substitution to bottled LPG.

\section{METHOD}

The problem of competition and substitution between energy sources established on a particular final use market are a common and a recurring theme on the energy planning affair. Under specific conditions a replacement process of a given energy source by another is inexorable, being only a matter of time. In order to analyze problems involving such kind of substitution process, these authors proposed the following set of coupled non-linear differential equations (NLDE) to describe the two products competition-substitution process:

$$
\begin{array}{ll}
\mathrm{dN} 1 / \mathrm{dt}=\varepsilon 1 . \mathrm{N} 1-\alpha 12 . \mathrm{N} 1 . \mathrm{N} 2 & \text { Equation 1 } \\
\mathrm{dN} 2 / \mathrm{dt}=\varepsilon 2 . \mathrm{N} 2+\alpha 21 . \mathrm{N} 1 . \mathrm{N} 2 & \text { Equation 2 }
\end{array}
$$

The time variation growth of $\mathrm{N} 1$ (displaced product) is proportional to itself and one subtractive term proportional to $\mathrm{N} 1 \mathrm{xN} 2$. Similarly, the time variation of $\mathrm{N} 2$ (substitute product) is proportional to itself plus one term proportional to $\mathrm{N} 1 \mathrm{xN} 2$. In this sense irepresent the $\mathrm{N} 1$ and $\mathrm{N} 2$ intrinsic or independent exponential growth rate, while the ijrepresent the substitution coefficients of N1 by N2 product. The symmetry of the coefficient $\quad$ ijmeans that the decreased fraction of $\mathrm{N} 1$ variation is added to $\mathrm{N} 2$ variation, which was adopted in this case.

This coefficient represents mathematically, in this reduced model, the sum of all techno-economic and social efforts - trustfulness, competitive prices, technology, utilization easiness, environmental appeal, marketing and fiscal incentives to replace N1 by N2 product. Thus, the knowledge or the estimation of the value is the most important and sensitive point of the numerical analysis and it will be shown that these $\square$ ijevaluations made in 2004 were reasonably good, as it will be shown.

The objective of this paper is:

- Verify the adherence of the forecasting method.

\footnotetext{
* Correspondingauthor, Tel: +55 1130912526

E-mail adress:kamimura@iee.usp.br
} 
- Highlight the merits of the model to make "what if..." uncertainty analysis and improve the communication between theoretical models appliers and decision makers.

\section{RESULTS}

In order to show the dynamic behavior of the Brazilian PNG market in the domestic sector from 2004 to 2014, we will analyze the reports released by the largest natural gas distribution company in Brazil, COMGÁSCorporation, responsible for the distribution and commercialization of Natural Gas in the State of São Paulo [2].In 2014 COMGÁS, at São Paulo State, was responsible for 56.8\% of the total Brazilian Natural Gas market consumed in the dwelling sector.The COMGAS distribution company invested current US \$106 million in 2004 and planned to invest another US \$ 354 million over the next five years. To get an idea of the optimistic economic climate experienced at the time, this amount of investment was overcoming in just two years (2005 and 2006). In the years 2007, 2008 and 2009 were invested another 630 million dollars. This enthusiasm continues in the following years (in millions of US current dollars): 243.1 (2010), 271.9 (2011), 301.4 (2012), 363.7 (2013) and 249.2 (2014). This last year begins to show a cooling of the optimistic mood.This same enthusiasm was not followed up by the other States considered in the replaceable LPG market.

This optimistic environment led COMGÁS to an expansion program of dwellingdistribution network, in 2004, so that the number of residences served by PNG increased from 442 thousand in 2004 to 1400 thousand in 2014 (3.2 times higher).However, the PNG consumption in São Paulo State did not follow such growth, so that in 2004, 105.1 million $\mathrm{m}^{3}$ were consumed, compared to 210.6 million $\mathrm{m}^{3}$ (approximately 2 times higher), leading to a decrease in the average consumption from $237.8 \mathrm{~m}^{3} / \mathrm{dwl}$ in 2004 to $150.4 \mathrm{~m}^{3} / \mathrm{dwl}$ in 2014 .

The reason of this decrease consumption per residence was due mainly to three factors:

1. The hydrological shortage, which shifted the supply of natural gas to thermoelectric generation, leading to an increase in gas consumption for this purpose of $54.8 \%$ in 2013 and $20.9 \%$ in 2014[3].

2. Economic structural change in the labor market leading to people to change eating habits,favoring feeding outside his residence.

3. Cooking habits change, favoring the consumption of processed foods.

The paper analyzed [1] shows how the ij transition rates or substitution coefficients were obtained and by the reasons pointed before it corresponds to a "weak" ScenarioBcase. The LPG substitution by PNG is an existing process in the dwelling sector since 1993, basically in São Paulo and Rio de Janeiro states. From that year until 2003 it is possible to determine the correspondents $i$ ij related to PNG consumptions for distinct adjacent pairs of years. These calculations lead to $\square$ ij values for the two elected scenarios. Excepting 1995 and 1999 atypical years, all calculated $\square$ ij display the same order values, that is, from 0.000105 to 0.000746 . The two evolutionary scenarios for numerical prospective calculations are the average values of "strong" PNG substitution occurred in the past (1994, 1996 and 2000) - Scenario A) and for "weak" substitution (1995, 1997, 1998, 2001, 2002 and 2003) - Scenario B). The corresponding ij average values are, respectively, equal to $\mathbf{0 . 0 0 0 6 3 2}$ for Scenario A) and $\mathbf{0 . 0 0 0 2 2}$ for Scenario B).

Other parameters required to run the model in 2004 are:

- Theinitial values for N1 (LPG market suitable for substitution) and N2 (PNG market). The LPG consumption in the dwelling sector of the following states: São Paulo, Rio de Janeiro, Paraná, Santa Catrina e Mato Grosso do Sul, in 2003, was $3,340.10^{3} \mathrm{tOE}$, in 2003. It was assumed that only $20 \%$ of this consumption is suitable for PNG substitution, v.g.668.10 ${ }^{3}$ tOE. This thermal substitution market is assumed to will grow up at $\square$ rate yearly, in accordance with population growth. The initial value N2 of PNG consumption was $172.10^{3}$ tOE in 2003, occurred basically in the States of São Paulo and Rio de Janeiro.

- $\square$ (LPG market growth, suitable for substitution) assumed to grow with the population growth rate $=1,5 \%$ per year.

- $\square$ (PNG independent market) assumed $=0$, since it was assumed that the growth of the PNG consumption is due only through the replacement of the LPG market portion, which evolves with $\square$ growth rate.

The Figure (1) shows for Scenario A (strong replacement) and B (weak replacement)the results predicted by the NLDE model for the residential PNG consumption ${ }^{1}$ and the values actually realized in the period $2003-2015$ [3]. 


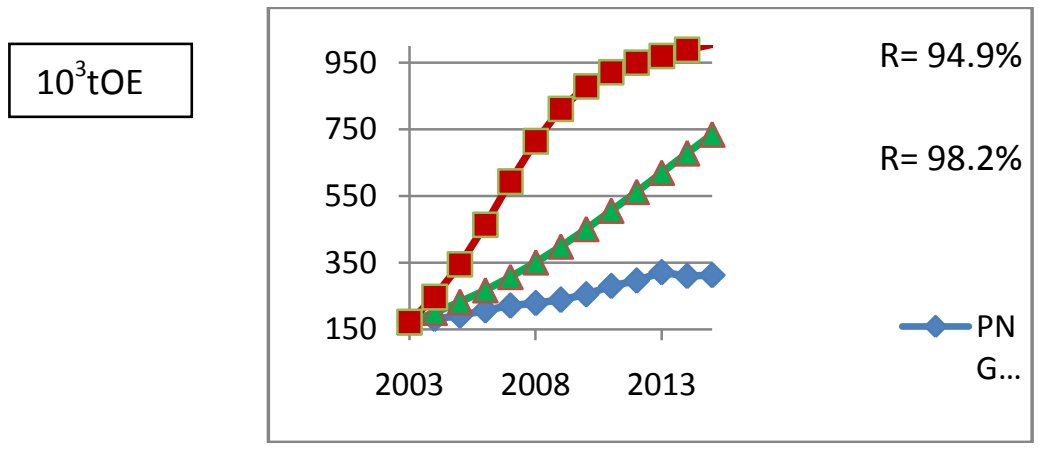

Figure 1.Results of the EDNL model to the final consumption of PNG in the dwelling sector, with "strong" and "weak" substitution (Sc.A) and (Sc.B), with initial values: $\square$ ij equal to $\mathbf{0 . 0 0 0 6 3 2}$ (Sc. A) and0.00022 (Sc.B), 1 $=1.5 \%$ per year, $\quad 2=0$, initial $\mathrm{N} 1=668.10^{3} \mathrm{tOE}$ and initial $\mathrm{N} 2=172.10^{3} \mathrm{tOE}$ [1]. PNG dwl corresponds to actual data series [3].

The linear correlation parameters $\mathrm{R}$ between the predicted data series and the actual historical series are quite high, especially for the series corresponding to a "weak" substitution (Scenario B) of Natural Gas replacing the LPG. However, the final value of predicted consumption is $135 \%$ higher for Scenario B and $222 \%$ higher for Scenario A.This huge deviationfor expected value was due to the optimistic mood of the suitable substitution LPG market evaluation made in 2004 (initial value for N1), assumed as $20 \%$ of the LPG consumption in the states of São Paulo, Rio de Janeiro, Parana, Santa Catarina and Mato Grosso do Sul.If this initial value for N1 is set as $10 \%$ (approximately the goal market for São Paulo State) instead of $20 \%$, namely $334 \times 103$ tOE instead of $668 \times 103$ tOE and keeping all other initial parameters (N2, $\square$ ijand ii)unchanged the result of the EDNL model would improve considerably, both in the final consumption value and in the linear correlation parameters R, comparing to actual data(Figure 2):This figure also shows that the $i \mathbf{j}$ transition parameter occurred in the period 2003 - 2015 correspond to Scenario B ("weak" substitution).

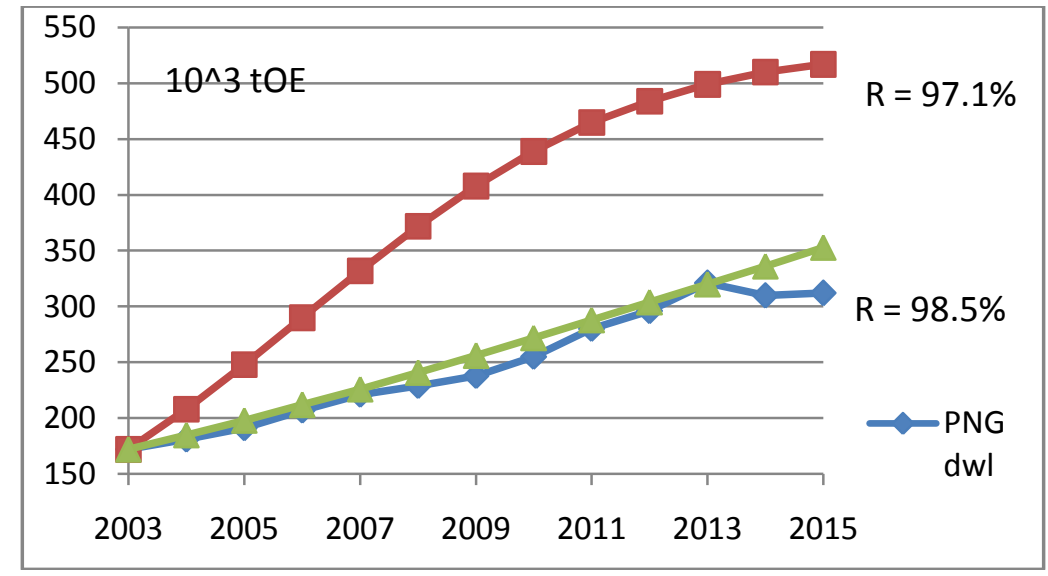

Figure 2. Results of the EDNL model to the final consumption of PNG in the dwelling sector, with "strong" and "weak" substitution (Sc.A) and (Sc.B), with initial values: $\square$ ij equal to $\mathbf{0 . 0 0 0 6 3 2}$ (Sc. A) and0.00022 (Sc.B), 1 $=1.5 \%, \quad 2=0$, initial $\mathrm{N} 1=334.10^{3} \mathrm{tOE}$ and initial $\mathrm{N} 2=172.10^{3} \mathrm{tOE}$. PNG dwl corresponds to actual data series [3].

Energy planning requires prospective activity, even though a precise forecasting event belongs to astrological oracle myth and superstition, as said by Ludwig Wittgenstein [4]: "We cannot infer future events from present events. The belief in this causal link is superstition. "

The NLDE model offers one possible alternative to express the robust and main behavior of substitution dynamic process between two competitive energy sources for the same market and can be useful to investigate different prospective scenarios. 


\section{REFERENCES}

[1] A. Kamimura, S.M.G. Guerra, I.L. Sauer. On the substitution of energy sources: Prospective of the natural gas market in the Brazilian urban transportation and dwelling sectors. Energy Policy 34, (2006), pp $(3583-3590)$.

[2] COMGAS. Annual Reports, 2014. http://ri.comgas.com.br/ptb/relatorios-anuais

[3] BEN. BalançoEnergético Nacional, 2016.MME - Ministry of Mines and Energy, Brasilia, DF, Brazil.<https://ben.epe.gov.br/default.aspx>

[4] L. Wittgenstein. Tratado Lógico Filosófico, Fundação CalousteGulbekian, Lisboa, Portugal (1985). 